\title{
JUURNAL.RU
}

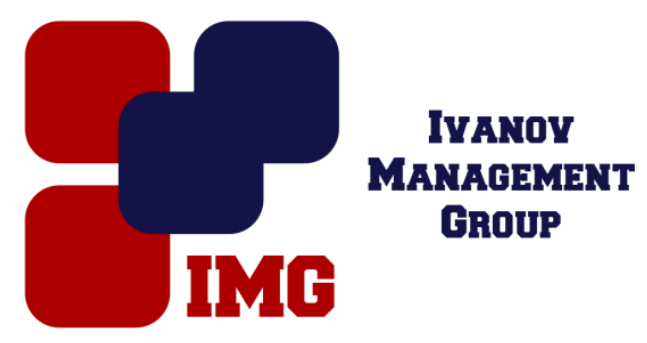

Кафиев И.Р.

Башкирский государственный аграрный университет Уфа, Россия

doi: $10.18411 / 1 \mathrm{j}-31-07-2017-35$

idsp 000001:1j-31-07-2017-35

\section{Тепловая схема замещения двухстороннего линейного асинхронного двигателя}

\section{Аннотация}

В статье предлагается эквивалентная тепловая схема замещения двухстороннего линейного асинхронного двигателя, позволяющая исследовать его надежность в электроприводе технологических машин АПК. Определены параметры схемы двухстороннего линейного асинхронного двигателя, применяемого в электроприводе жерновой мельницы.

Ключевые слова: тепловая схема; двухсторонний линейный асинхронный двигатель; надёжность; изоляция обмотки; жерновая мельница.

Развитие современного сельского хозяйства невозможно представить без применения электропривода.

В настоящее время наметилась тенденция расширения области применения в сельском хозяйстве электроприводов, построенных на базе линейных асинхронных двигателей (ЛАД).

Отсутствие электрического контакта со вторичным элементом, возможность получения большого диапазона линейных скоростей и перемещений без использования кинематических связей, конструктивная простота и высокий коэффициент полезного действия способствовали разработке и созданию большого количества линейных электроприводов для сельскохозяйственных машин. 
На базе ЛАД разработаны инерционный конвейер для транспортирования сельскохозяйственных продуктов [1], устройство для измельчения и помола зерновых культур [2], [3] и т. д.

Несмотря на большое количество разработок, вопросы надежности ЛАД, используемых в сельском хозяйстве, изучены недостаточно [4].

Как указано в [5], в подавляющем большинстве случаев (85..95\%) отказы асинхронных двигателей связаны с повреждением изоляции обмоток. Основным фактором, влияющим на надежность изоляции электрических машин, является тепловое старение.

Поэтому для исследования надежности ЛАД необходимо построить его эквивалентную тепловую схему.

В работе предлагается тепловая схема замещения двухстороннего ЛАД, в которой обмотка первого индуктора представляется первым телом, сталь (магнитопровод) первого индуктора - вторым телом, вторичный элемент (ВЭ) третьим телом, обмотка второго индуктора - четвертым телом, а сталь (магнитопровод) второго индуктора является пятым телом (рисунок 1).

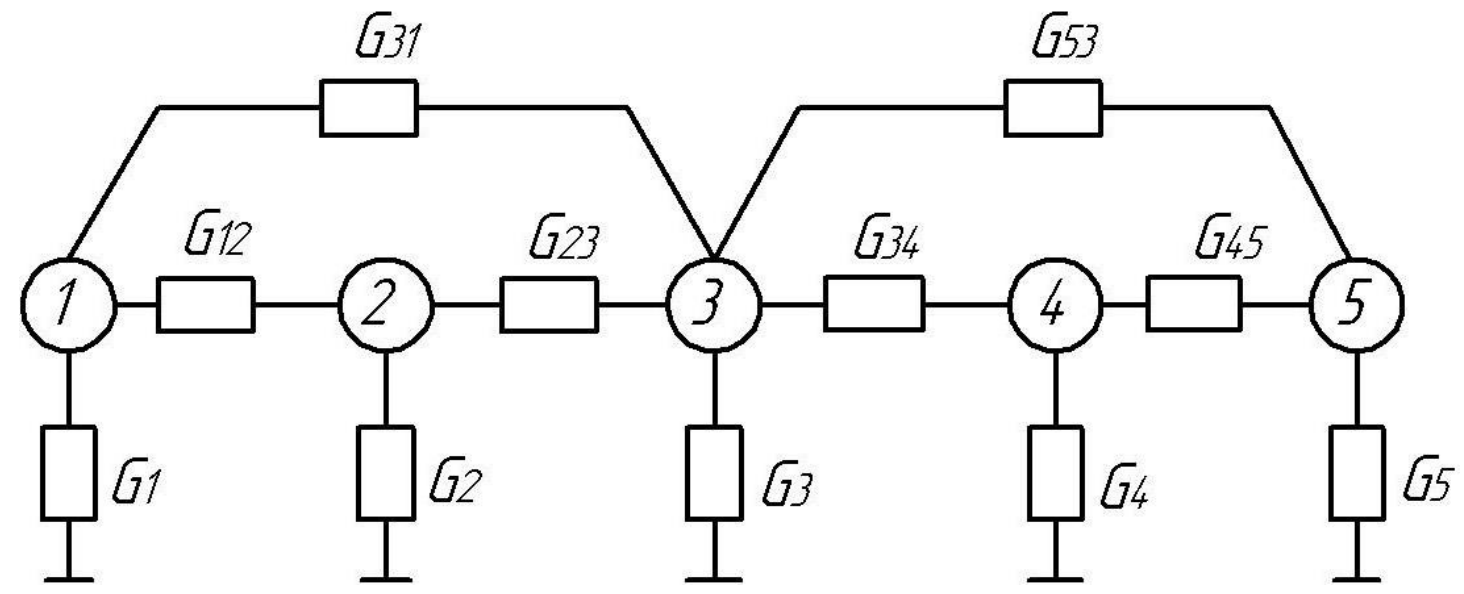

Рисунок 1 Тепловая схема замещения двухстороннего линейного ЛАД:

1 -обмотка первого индуктора; 2 - сталь первого индуктора;

3 - вторичный элемент ЛАД; 4 - обмотка второго индуктора;

5 - сталь второго индуктора; G1, G2, G3, G4, G5 - тепловые проводимости от обмотки и стали первого индуктора, ВЭ, обмотки и стали второго индуктора в окружающую среду; G12, G23, G31, G34, G45, G53тепловые проводимости между телами

Расчет значений тепловых проводимостей схемы проводился в соответствии с методиками, представленными в [6] и [7] для ЛАД в приводе жерновой мельницы [8]. При этом в приводе использовались две одинаковые ЛАД, а магнитные зазоры между индукторами и ВЭ принимались равными.

Результаты расчетов параметров эквивалентной тепловой схемы двухстороннего ЛАД приведены в таблицах 1 и 2. 
Таблица 1.

Значения тепловых проводимостей от элементов ЛАД в окружающую среду

\begin{tabular}{|c|c|c|c|c|c|}
\hline Параметр & $\mathrm{G}_{1}$ & $\mathrm{G}_{2}$ & $\mathrm{G}_{3}$ & $\mathrm{G}_{4}$ & $\mathrm{G}_{5}$ \\
\hline Ед. изм. & 0,64 & 0,832 & 32,17 & 0,64 & 0,832 \\
\hline Значение & $0,67{ }^{\circ} \mathrm{C}$ &
\end{tabular}

Таблища 2.

Значения тепловых проводимостей между элементами двухстороннего ЛАД

\begin{tabular}{|c|c|c|c|c|c|c|}
\hline Параметр & $\mathrm{G} 12$ & $\mathrm{G} 23$ & $\mathrm{G} 31$ & $\mathrm{G} 34$ & $\mathrm{G} 45$ & $\mathrm{G} 53$ \\
\hline Ед. изм. & \multicolumn{7}{|c|}{$\mathrm{BT} /{ }^{\circ} \mathrm{C}$} \\
\hline Значение & 53,34 & 0,095 & 0,105 & 0,105 & 53,34 & 0,095 \\
\hline
\end{tabular}

Рассчитанные параметры могут быть использованы при моделировании тепловых процессов в двухстороннем ЛАД привода жерновой мельницы.

***

1. Патент 2422348 Российская Федерация, МПК В 65 G 27 24. Инерционный конвейер / Р.С. Аипов, С.В. Акчурин, А.В. Линенко, М.Ф. Туктаров . № 2010110857/11; заявл. 22.03.2010; опубл. 27.06.2011, Бюл. №11. 3 с.

2. Аипов Р.С. Мельница для производства «живой» муки / Р.С. Аипов, Р. Р. Нугуманов //Сельский механизатор. 2012. № 8. С. 27.

3. Патент № 2482920 Российская Федерация, МПК В02С 7/16. Устройство для измельчения твердых материалов / Р.С. Аипов, Р.Р. Нугуманов. №2012106826/13; заявл. 24.02.2012 г.; опубл. 27.05.2013 г., Бюл. № 15. 7 с.

4. Аипов Р.С. К вопросу о надежности электроприводов сельскохозяйственных машин / Р.С. Аипов, И.Р. Кафиев // Аграрная наука в инновационном развитии АПК: материалы международной научно-практической конференции в рамках XXVI Международной специализированной выставки «Агрокомплекс-2016». Часть III. Уфа: Башкирский ГАУ, 2016. С. 3-6.

5. Кузнецов Н.Л. Надежность электрических машин [Текст]: учеб. пособие для вузов / Н.Л. Кузнецов. М.: Издательский дом МЭИ, 2006. 432 с.

6. Борисенко А.И. Охлаждение промышленных электрических машин / А.И. Борисенко, О.Н. Костиков, А.И. Яковлев. М.: Энергоатомиздат, 1983. 296 с.

7. Проектирование электрических машин: учеб. для вузов / И. П. Копылов, Ф. А. Горяинов, Б. К. Клоков и др.; Под ред. И. П. Копылова. М.: Энергия, 1980. 496 с.

8. Патент № 2546860 Российская Федерация, МПК В 02 С7/08, В 02 С7/16.Устройство для измельчения / Р.С. Аипов, Р.Р. Нугуманов, А.В. Линенко. - №2013153279/13; заявл. 29.11.2013; опубл. 10.04.2015 г., Бюл. № 10. 7 с. 